\title{
Internuclear ophthalmoplegia
}

An electro-oculographic study of peak angular saccadic velocities

\author{
A. C. BIRD* AND J. LEECH \\ From the MRC Hearing and Balance Unit, Institute of Neurology, National Hospital for \\ Nervous Diseases, London
}

Internuclear ophthalmoplegia is a well-recognized disorder of horizontal eye movements, characterized by impairment of adduction (Holmes, 192I) and nystagmus of the abducting eye (Harris, 1944). Studies of human histopathology (Cogan, Kubic, and Smith, 1950; Christoff, Anderson, Nathanson, and Bender, 1960; Kupfer and Cogan, 1966) and animal experiments (Carpenter and McMasters, 1963; Carpenter and Strominger, 1965) show that it can be attributed to a lesion of the medial longitudinal fasciculus between the levels of the sixth and third nerve nuclei, on the side of the abnormally adducting eye. It has been inferred that the lesion affects axons arising from cells in the paramedian pontine reticular formation and passing to the medial rectus motor neurons in the oculomotor nerve (Bender and Weinstein, 1950; Carpenter and McMasters, 1963; Carpenter and Strominger, 1965; Fuchs and Luschei, 1970). However, recent anatomical studies have failed to demonstrate direct connexions between the paramedian pontine reticular formation and the ocular motor nuclei (Grabiel, 1975). In addition, the interneurons described by Baker and Highstein (1975) which relay from the sixth and third nuclei may be responsible for the mutual co-ordination of the two eyes during horizontal eye movements, and dysfunction of these neurons may be relevant to the pathogenesis of internuclear ophthalmoplegia.

The impairment of adduction is variable, the most severe lesions causing complete loss of adduction beyond the midline during contralateral gaze. In early reports, the clinical diagnosis depended on the recognition of a limited range of adduction. However, more recently it has been recognized that a less severe lesion may cause no apparent limitation in the excursion of the adducting eye, and the only clinical manifestation of the lesion may be reduced adduction velocity during horizontal saccades (Smith and David, 1964; Nelson and Engrov, 1969;

\footnotetext{
*Also of Institute of Ophthalmology, Moorfields Eye Hospital, London

Address for reprints: A. C. Bird, FRCS, Department of Clinical Ophthalmology, Moorfields Eye Hospital, City Road, London ECIV 2PD
}

Cogan, 1970; Bird and Sanders, 1970; Dell'Osso, Robinson, and Daroff, 1974; Metz, 1976). Identification of internuclear ophthalmoplegia may be further complicated by the coexistence of lesions involving the neural pathways controlling conjugate eye movements or the sixth nerve (Cogan, 1970).

In the early part of this century the characteristics of saccadic eye movements were defined (Dodge and Cline, 1901; Dodge, 1903) and the properties of saccades have been identified more precisely during the last two decades (Westheimer, 1954; Yarbus, 1956; Mackensen, 1958; Hyde, 1959; Rashbass, 196I; Robinson, 1964; Cook, Stark, and Zuber, 1966; Fricker, 1971 ; Ishikawa and Terakado, 1973; Boghen, Troost, Daroff, Dell'Osso, and Birkett, 1974). It has been shown that a saccade is the result of a pulse-step change in innervation in which there is intense innervation of the agonist muscle and disfacilitation of the antagonist (Miller, 1958; Tamler, Marg, Jampolsky, and Nawratzki, 1959). Contraction of the agonist muscle results from a train of high-frequency pulses in the ocular motor neurons, and even in small saccades the frequency approaches the maximum attainable in low threshold units. The size of the saccade is related to the number of excited neurons, the discharge rate of each neuron, and the length of the pulse of excitation. Saccades of over $20^{\circ}$, and those occurring away from the midline, cause near maximal innervation of all agonist motor neurons, and the characteristics of such eye movements are determined largely by the duration of excitation (Fuchs and Luschei, 1970; Robinson, 1970).

Peak velocity measurements have been used to characterize saccades. Such measurements may substantiate the clinical observation of slow saccades as a clinical sign of disease involving the neural mechanisms controlling eye movements (Gowers, 1879; Holmes, I921; Starr, 1967). Reports have suggested the usefulness of these techniques in the detection of internuclear ophthalmoplegia (Bird and Sanders, 1970; Metz, 1976).

In this paper we report the results of quantitative assessment of peak angular velocities in a group of normal subjects and in a group of patients with a full range of ocular movements but with suspected 
slow adduction on horizontal conjugate gaze indicating internuclear ophthalmoplegia. The measurements in the two groups were compared in order to prove the clinical sign, and to assess the incidence of associated subclinical ocular motor deficits.

\section{Method}

Eighteen patients with nervous system disease were chosen for study because internuclear ophthalmoplegia was suspected. Seventeen patients had multiple sclerosis and one (Patient I8) had a subarachnoid haemorrhage associated with clinical signs of brain stem dysfunction. Of the patients with multiple sclerosis, the history of disease varied from two months to ro years and nine had no symptoms referrable to the visual system. In all patients adduction appeared to be slower than abduction during horizontal saccades, although in all but two cases (Cases 6,16 ) adduction appeared full, and in all it was more than $30^{\circ}$ beyond the midline. Twenty-five normal people were used as a comparison group. All normal subjects and patients studied had a visual acuity of $6 / 6$, and none had used sedatives, hypnotics, or anticonvulsants during the week before testing.

All subjects were placed in a dental chair with a chin rest for stabilization. Ocular saccades of each eye were recorded by electro-oculography using electrodes over the medial and lateral canthi bilaterally, and an indifferent electrode was placed centrally over the nasion. The electrodes were a modification of those described by Hallpike, Hood, and Trinder (1960). A DC amplifier was used (Elema Schonander universal amplifier EMT 12) in conjunction with a linear ink jet writer (Elema Schonander minograf ' $6 r$ '). This amplifier/recorder combination gave a linear frequency response up to $500 \mathrm{~Hz}$ falling off to 70 per cent amplitude at $650 \mathrm{~Hz}$. Peak velocities were assessed by measuring graphically the steepest part of the record during the ocular deviation.

Fixation targets were tungsten filament bulbs viewed through a $2 \mathrm{~mm}$ aperture on a black background. The central target was $60 \mathrm{~cm}$ in front of the corneae, and two further targets were set at a visual angle of $30^{\circ}$ to either side of the central target. After calibration, the targets were illuminated one at a time and the subject was asked to look carefully at the light. Only $30^{\circ}$ movements were asked for-that is, centre to left, left to centre, centre to right, right to centre. The test was continued until at least five accurate saccades had been recorded in each of these directions. Calibration was repeated at intervals during the test. Individual peak velocity values were used to calculate mean velocity and the 95 per cent confidence limits for each movement. Individual values were used to compare the results in patients with those in the normal group using Student's $t$ test.

\section{Results}

The mean peak saccadic velocities and 95 per cent confidence limits for the normal group are shown in Table I. Four of the 200 mean individual values obtained were above the confidence limits and none was below. Student's $t$ test was used to compare adduction and abduction velocities of each of the four saccades, and adduction was signicantly faster in each case $(\mathrm{P}<0.00 \mathrm{I})$. A similar comparison showed that centring was faster than decentring $(\mathrm{P}<0.00 \mathrm{I})$.

The mean peak velocities of eye movements in the group with internuclear ophthalmoplegia are shown in Table I, and of each patient in Table II. Adduction and abduction peak velocities were compared and abduction was significantly the faster $(P<0.001)$, and in this respect the group differed from the normal subjects $(P<0.001)$. Adduction was slower than abduction bilaterally in all patients. A discriminant analysis was made on each patient and normal subject and everyone was correctly identified as belonging to the appropriate group.

The wave-form of the adducting eye described during saccades differed from normal but varied from one patient to another. In some the movement was slow but the symmetry was unaltered (Fig. Ia), while in others there was progressive fall-off of angular velocity as the saccade progressed (Fig. I $b, c$ ).

Table I Mean of peak eye velocities and 95 per cent confidence limits (in parentheses) during $30^{\circ}$ horizontal saccades of 25 normal subjects and 18 patients with internuclear ophthalmoplegia (INO)

\begin{tabular}{|c|c|c|c|c|c|c|c|c|}
\hline \multirow{3}{*}{ Group } & \multicolumn{4}{|l|}{ Right gaze } & \multicolumn{4}{|l|}{ Left gaze } \\
\hline & \multicolumn{2}{|c|}{ Left to straight ahead* } & \multicolumn{2}{|c|}{ Straight ahead to right* } & \multicolumn{2}{|c|}{ Right to straight ahead* } & \multicolumn{2}{|c|}{ Straight ahead to left" } \\
\hline & Right eye & Left eye & Right eye & Left eye & Right eye & Left eye & Right eye & Left eye \\
\hline Normal & $\begin{array}{l}464 \\
(584-343)\end{array}$ & $\begin{array}{l}506 \\
\left(6_{34}-379\right)\end{array}$ & $\begin{array}{l}453 \\
(582-324)\end{array}$ & $\begin{array}{l}504 \\
(627-381)\end{array}$ & $\begin{array}{l}531 \\
(660-402)\end{array}$ & $\begin{array}{l}510 \\
(642-347)\end{array}$ & $\begin{array}{l}529 \\
(669-389)\end{array}$ & $\begin{array}{l}470 \\
(601-340)\end{array}$ \\
\hline INO & $\begin{array}{l}323 \\
(551-94)\end{array}$ & $\begin{array}{l}231 \\
(397-66)\end{array}$ & $\begin{array}{l}298 \\
(520-75)\end{array}$ & $\begin{array}{l}162 \\
(340-0)\end{array}$ & $\begin{array}{l}202 \\
(370-34)\end{array}$ & $\begin{array}{l}317 \\
(521-113)\end{array}$ & $\begin{array}{l}157 \\
(341-0)\end{array}$ & $\begin{array}{l}309 \\
(480-138)\end{array}$ \\
\hline
\end{tabular}

* $=30^{\circ}$ saccade 
Table II Mean of peak eye velocities during $30^{\circ}$ saccades of each patient with internuclear ophthalmoplegia. The first 17 patients had multiple sclerosis and the last had suffered a subarachnoid haemorrhage with signs of brain stem dysfunction

\begin{tabular}{|c|c|c|c|c|c|c|c|c|c|}
\hline \multirow{3}{*}{ Patient } & \multirow{3}{*}{$\begin{array}{l}\text { Length of } \\
\text { disease } \\
\text { (years) }\end{array}$} & \multicolumn{4}{|l|}{ Right gaze } & \multicolumn{4}{|l|}{ Left gaze } \\
\hline & & \multicolumn{2}{|c|}{$\begin{array}{l}\text { Left to straight } \\
\text { ahead* }\end{array}$} & \multicolumn{2}{|c|}{$\begin{array}{l}\text { Straight ahead to } \\
\text { right* }\end{array}$} & \multicolumn{2}{|c|}{$\begin{array}{l}\text { Right to straight } \\
\text { ahead* }\end{array}$} & \multicolumn{2}{|c|}{$\begin{array}{l}\text { Straight ahead to } \\
\text { left* }\end{array}$} \\
\hline & & Right eye & Left eye & Right eye & Left eye & Right eye & Left eye & Right eye & Left eye \\
\hline $\mathbf{I}$ & 3 & 340 & 310 & 326 & 208 & 218 & $33^{8}$ & 40 & 328 \\
\hline 2 & 4 & 212 & 232 & 158 & 96 & 185 & 432 & 126 & $33^{8}$ \\
\hline 3 & 3 & 354 & 267 & 294 & 240 & 151 & 313 & 143 & 233 \\
\hline 4 & $2 / 12$ & 581 & 365 & 510 & 330 & 438 & 445 & 327 & $44 I$ \\
\hline 5 & 5 & 400 & 242 & 363 & 227 & 339 & 418 & 295 & 358 \\
\hline 6 & 5 & 218 & 185 & 185 & 39 & 133 & 175 & 97 & 193 \\
\hline 7 & 6 & 187 & 148 & 221 & 98 & 130 & 217 & 99 & 188 \\
\hline 8 & I & 410 & 275 & 392 & 213 & 178 & 470 & 136 & 357 \\
\hline 9 & 3 & 353 & 285 & 234 & 181 & 308 & 387 & 293 & 365 \\
\hline 10 & 6 & 333 & 143 & 315 & 125 & 97 & 284 & 77 & 301 \\
\hline I I & $6 / 12$ & 166 & 165 & 227 & 115 & 130 & 153 & 100 & 212 \\
\hline 12 & 4 & 379 & 277 & 342 & 247 & 200 & 333 & 140 & 378 \\
\hline 13 & $I \frac{1}{2}$ & 302 & 265 & 260 & 218 & 235 & $\mathbf{2 8 8}$ & 159 & 306 \\
\hline 14 & 2 & 532 & 103 & 383 & 271 & 137 & 393 & 99 & 429 \\
\hline 15 & 10 & 399 & 218 & 383 & 128 & 224 & 445 & 197 & 507 \\
\hline 16 & 7 & 217 & 186 & 167 & 40 & 167 & 169 & 89 & 188 \\
\hline 17 & 2 & 587 & 161 & 430 & 129 & 198 & 260 & 166 & 316 \\
\hline 18 & & 175 & 190 & 226 & 97 & 218 & I 94 & 129 & 298 \\
\hline
\end{tabular}

* $=30^{\circ}$ saccade

Occasionally two distinct fast phases were recorded within the saccade (Fig. $1 b, c$ ). In each patient the wave-form was reproduced consistently for a particular saccade, although adduction in one direction often differed from adduction in the other.

The group of patients with internuclear ophthalmoplegia had significantly slower abduction than the normal subjects in all saccadic movements $(P<0.001)$. In eight, abduction peak velocities of both eyes were below the 95 per cent confidence limit calculated from the normal group, and in a further three abduction was slow in one eye. In a majority abduction slowing was more pronounced during the decentring than the centring movement.

\section{Discussion}

It was established recently that ocular peak angular velocity is higher during large saccades than small, although the relationship is not linear and reaches its greatest at about $25^{\circ}$ (Hyde, 1959; Cook, Stark, and Zuber, 1966; Boghen and others, 1974). There is some variation in the findings concerning normal peak velocities and the relative peak velocities of different eye movements. Average peak velocities during $30^{\circ}$ saccades measured in a series of normal subjects have been variously reported as $580^{\circ}$ per second (Westheimer, 1954); $529^{\circ}$ per second (Hyde,
1959); $452^{\circ}$ per second (Ishikawa and Terakado, 1973), and $428^{\circ}$ per second (Boghen and others, 1974). Speeds of over $600^{\circ}$ per second have been recorded and Boghen and others (1974) consider $200^{\circ}$ per second as the lower limit of normal. It has been reported that temporal saccades are faster than nasal saccades (Robinson, 1964; Fricker, 1971) and that they are equal in both directions (Hyde, 1959); that adduction saccades are faster than abduction saccades during large eye movements (Boghen and others, 1974) and that they are equal in small saccades (Boghen and others, 1974). It has also been reported that centring movements with respect to the primary position are faster than decentring (Hyde, 1959; Cook and others, 1966). The variability of results may be related to some extent to the different experimental techniques used. The stimuli used include alternating fixed and moving targets, and the recording systems include high-speed photography, corneal and contact lens reflexion, AC and DC electrooculography, contact lens scleral search coil in a magnetic field, and infrared reflection. In some studies the measurements were restricted to accurate eye movements only, while in others no such restriction was made. The limited data are another likely source of discrepancy; in many studies few subjects were used and few movements analysed. 

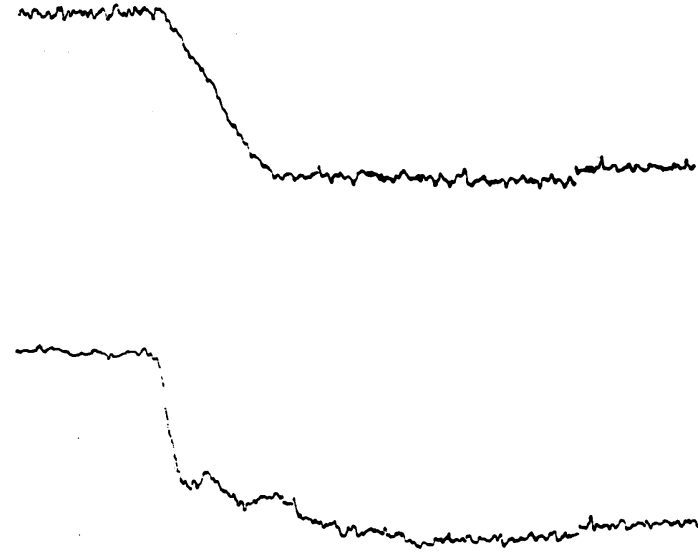

(a)
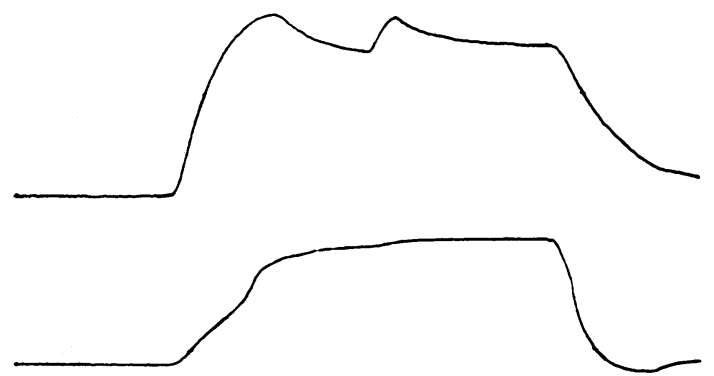

(b)

This is important, since it has been shown that there is considerable intersubject variation in peak velocities for the same movements and that the speed may vary in the same subject (Boghen and others, 1974). Therefore, there appear to be no accepted data for peak velocities during saccades at present, and as Boghen and others (1974) emphasized, normal values have to be established by each laboratory.

That the average peak adduction velocity in the 25 normal subjects in this series was significantly faster than the abduction velocity is in complete agreement with the findings of Boghen and others (1974). Adduction was consistently faster than abduction in 22 of the 25 subjects during all eye movements measured. The speeds are somewhat faster than those recently published but there was considerable inter- and intrasubject variability.
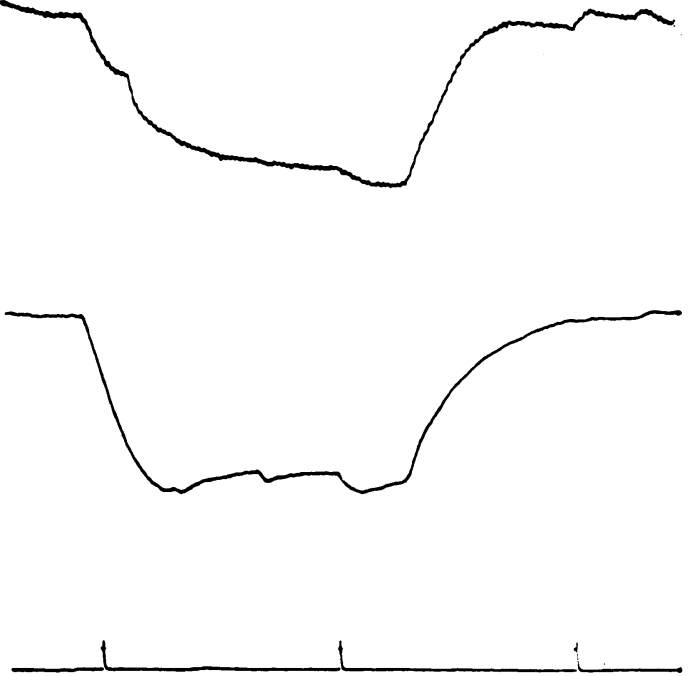

(c)

FIG. I EOG records during $30^{\circ}$ saccades. In each case the upper trace was derived from right eye and the lower from the left, and a movement to right is indicated by an upward deflexion of the trace and to the left by a downward deflexion.

(a) The adduction movement is slower than abduction, but is relatively symmetrical. (b) Left eye adduction shows two relatively fast phases whereas right adduction becomes slower as movement proceeds. (c) Right adduction shows two distinct fast phases and left adduction becomes slower as movement proceeds

Of the 18 patients studied all had peak adduction velocities which were below the estimated lower limit of normal, and had slow adduction when the adducting and abducting eyes were compared. Characteristically, peak adduction velocities were relatively slower during the movement away from the midline and towards the limit of adduction, than during movement towards the midline, and in three a relative slow movement was detected only during the decentring movement. It can be concluded that measurement of peak velocities is useful in detecting internuclear ophthalmoplegia, or confirming the presence of suspected slow adduction. In this way the procedure may be critical in demonstrating unequivocally the presence of a second lesion in the central nervous system when a patient with restricted central nervous system deficit, such as optic neuritis or spastic paraplegia, is suspected of having multiple sclerosis.

It appears that slow saccades rather than limited saccades are characteristic of mild internuclear ophthalmoplegia' due to primary intrinsic demyelination. It has been established that, in its most severe form, demyelination causes a block in axonal conduction (McDonald and Sears, 1970). Such a 
lesion in the internuclear pathways would be expected to cause limitation of the range of adduction during horizontal saccades.

However, milder lesions render the axon incapable of conducting high-frequency signals and cause delay in conduction of impulses by the axon (McDonald and Sears, 1970). The ocular motor nerves are characterized by the high frequency of nerve impulses (Robinson, 1970); if the central ocular motor system is similar in this regard an element of nerve block may be induced by demyelination. Such an alteration in conduction would cause the movement to be hypometric and slow, but occupy normal time. It is likely that the impulse frequency required to maintain the eyes in the eccentric position would be less affected so that after the initial saccadic movement the adducting eye would drift slowly on to target (Robinson, 1971). That such a wave-form was recorded (Fig. I $b$, c) suggests that an element of conduction block of high-frequency impulses plays a part in producing disordered adduction in internuclear ophthalmoplegia. Unequal slowing of conduction of internuclear fibres in the medial longitudinal fasciculus would lengthen the overall pulse of excitation generating the saccade and reduce its peak frequency. This might account for slow movement with symmetrical wave-form (Fig. Ia). It is somewhat more difficult to account for the two distinct fast phases which were recorded during the single adduction movement (Fig. $\mathrm{I} b, c$ ). It is unlikely that these two movements were formulated separately by the brain stem oculomotor generators since uniocular and vergence movements are characteristically slow (Weber and Daroff, 1971). Such a movement would occur if a lesion caused delayed conduction in some of the nerve fibres connecting the saccadic generator with the medial rectus motor pool leaving others intact. This would result in two pulses of adduction excitation at the oculomotor nerve and the interval between the two would correspond to the relative delay in one fibre population compared with the other.

The results also show that abduction speeds in these patients with internuclear ophthalmoplegia were slow. Slowing of abduction may be due to lack of inhibition of the medial rectus muscle antagonizing the movement (Loeffler, Hoyt, and Slatt, r 966). However, no clinical correlation of this lack of inhibition has yet been shown and we have not demonstrated any correlation between the severity of the internuclear ophthalmoplegia and abduction slowing. Therefore, there is no evidence that slow abduction is an integral part of the internuclear ophthalmoplegia. Slow abduction may have been caused by concurrent lateral rectus paresis due to lesions affecting the sixth nerve or the connexions between the pontine reticular formation and the sixth nerve nucleus, as proposed by Rothstein and Alvord (197I). Slowing of eye movements has been described in patients with lateral rectus paresis (Metz, Scott, O'Meara, and Stewart, 1970) but not in the absence of restricted movement.

Alternatively, slow abduction in these patients with internuclear ophthalmoplegia may be due to a lesion of the supranuclear mechanisms governing horizontal saccades, although no patients had a previously recognized horizontal gaze paresis. Reduction of saccadic peak velocity has been recognized as a manifestation of horizontal gaze paresis even in the presence of a full range of ocular movements (Gowers, 1879; Holmes, 1921; Starr, 1967). The occurrence of horizontal gaze paresis in patients with internuclear ophthalmoplegia has been emphasized in the past (Cogan, 1970) but the frequency of this association has not yet been established. In this series of patients with internuclear ophthalmoplegia, this feature occurred in as many as $I 1$ out of a total of 18 , and was unilateral in three and bilateral in eight. Normal abduction velocities in the remaining five patients do not necessarily indicate the integrity of the supranuclear gaze mechanisms since in four the peak velocities were close to the 95 per cent confidence limit, and the incidence of supranuclear lesions may be even higher than indicated by these figures. Gaze paresis and the internuclear ophthalmoplegia may be due to the same lesion (Fisher, 1967), but it is equally possible that more than one lesion caused the multiple ocular motor deficits in these patients. All patients studied had disease which was multifocal in nature, and all had clinical evidence of more than one lesion; it is relevant that four of the five with normal abduction velocities had a short history of the disease.

The high frequency of gaze paresis may be relevant to the nystagmus which is so characteristic of internuclear ophthalmoplegia. The nystagmus is usually attributed to the abducting eye only, but in most patients nystagmus can be detected in the adducting eye also (Fig. $\mathrm{I} b$ ); the nystagmus is less in the adducting eye so that it is asymmetrical rather than unilateral. The nystagmus on extremes of horizontal gaze may be due to gaze paresis, the low frequency and irregularity of the nystagmus being characteristic of gaze paretic nystagmus (Jung and Kornhuber, 1964). Asymmetry of eye movements is well recognized during optokinetic nystagmus (Smith and David, 1964) and postrotational nystagmus (Sjroky, Kieicova, and Ymazah, 1973), and has been attributed to the small excursion of slow adduction saccades and superadded convergence tone (Dell'Osso and others, 1974). Similarly the asymmetry of the nystagmus on lateral gaze could be attributed to the 
internuclear ophthalmoplegia. It has been shown in many of our patients that adduction saccades become slower as the eye nears full adduction, and this would certainly account for the high degree of asymmetry of the nystagmus on extreme lateral gaze, and the difficulty in detecting the movement of the adducting eye.

\section{Summary}

Peak angular saccadic velocities were measured during $30^{\circ}$ saccades in 18 patients with internuclear ophthalmoplegia who had full or nearly full adduction range, and 25 normal subjects. The following observations were made:

I. In the normal group adduction velocities were significantly faster than abduction velocities and centring movements were faster than decentring movements.

2. In patients with internuclear ophthalmoplegia adduction movements were significantly slower than in normal subjects and were significantly slower than abduction velocities.
3. Abduction velocities in patients with internuclear ophthalmoplegia were significantly slower than abduction velocities in normal subjects.

It was concluded that measurements of peak angular velocities during saccades may be useful in detecting internuclear ophthalmoplegia or confirming the presence of suspected internuclear ophthalmoplegia. Slow abduction suggests that many patients with internuclear ophthalmoplegia (60 per cent in this series) have lesions affecting the supranuclear pathways subserving horizontal conjugate gaze.

We should like to thank Dr J. D. Hood, who advised us during this work, the consultants of the National Hospital for Nervous Diseases who allowed us to study their patients, Dr M. Gresty, who advised us concerning the manuscript, and Miss Jayne Fisher for secretarial help. We should also like to thank Mr B. Augier and Mr H. Donovan who performed the statistical analyses. We are particularly grateful to those normal subjects who comprised the comparison group.

\section{References}

BAKER, R., and HIGHSTEIN, S. M. (1975) Brain Res., 91, 292 Bender, M. B., and Weinstein, E. A. (1950) Res. Publ. Ass. nerv. ment. Dis., 28, 414 BIRD, A. C., and SANDERS, M. D. (1970) Trans. ophthal. Soc. U.K., 90, 417 BOGHEN, D., TROOST, B. T., DAROFF, R. B., DELl'OSSO, L. F., and BIRKETT, J. E. (1974) Invest. Ophthal., 13, 619 CARPENTER, M. B., and MCMASTERS, R. E. (1963) Arch. Neurol. (Chic.), 8, 347

- and STROMINGER, N. L. (1965) \}. comp. Neurol., 125, 4 I

Christoff, N., ANDerson, P. J., NAThanson, M., and Bender, M. B. (1960) Arch. Neurol. (Chic.), 2, 293 COGAN, D. G. (1970) Arch. Ophthal., 84, 583

-, KUBIC, C. S., and SMITH, W. L. (1950) Ibid., 44, 783

COOK, G., STARK, L., and ZUBER, B. L. (1966) Ibid., 76, 589

Dell'osso, L. F., ROBINSON, D. A., and DAROFF, R. B. (1974) Arch. Neurol. (Chic.), 31, 38

Dodge, R. (1903) Amer. F. Physiol., 8, 307

$\longrightarrow$, and Cline, T. S. (1901) Psychol. Rev., 8, 125

FISHER, C. M. (1967) भ. Neurol. Neurosurg. Psychiat., 30, 383

FRICKER, S. J. (1971) Invest. Ophthal., 10, 724

FUCHS, A. F., and LUSCHEI, E. S. (1970) F. Neurophysiol., 33, 382

GOWERS, W. R. (1879) Brain, 2, 39

GRABIEL, A. (1975) Communication at the Rochester Meeting of The Society for Neurosciences, vol. 5, in press HALLPIKE, C. S., HOOD, J. D., and TRINDER, D. (1960) Confin. neurol. (Basel), 20, 232

HARRIS, W. (1944) Brit f Ophthal., 28, 40

HOLMES, G. (1921) Ibid., 5, 241

HYDE, J. (1959) Amer. F. Ophthal., 48, 85

ISHIKAWA, s., and TERAKADO, R. (1973) $\mathscr{f} a p . \mathcal{F}$. Ophthal., I7, I I

JUNG, R., and KORNHUBER, H. H. (1964) 'The Oculomotor System', ed. M. B. Bender, p. 428. Harper \& Row,

New York

KUPFER, C., and COGAN, D. G. (1966) Arch. Ophthal., 75, 484

LOEFFler, J. D., HOYT, W. F., and Slatt, B. (1966) Arch. Neurol. (Chic.), 15, 664

MACKENSEN, J. (1958) v. Graefes Arch. Ophthal., 160, 47

MCDONALD, W. I., and SEARS, T. A. (1970) Brain, 93583

METZ, H. S. (1976) Amer. F. Ophthal., 81 296

- SCOTT, A. B., O'MEARA, D., and STEWART, H. L. (1970) Arch. Ophthal., 84453

MILler, J. E. (1958) Amer. Э. Ophthal., 46183

NELSON, J. R., and ENGROV, L. (1969) Neurology (Minneap.), 19288

Rashbass, c. (1961) Y. Physiol. (Lond.), 159, 326 
ROBINSON, D. A. (1964) Ibid., 174, 245

(1970) F. Neurophysiol., 33, 393

(1971) 'Control of Eye Movements', eds P. Bach-y-Rita, C. C. Collins, and J. E. Hyde, p. 5 rg. Academic

Press, New York and London

ROTHSTEIN, T. L., and ALVORD, E. c. (1971) Arch. Neurol. (Chic.), 24, r9 I

SMITH, J. L., and DAVID, N. J. (1964) Neurology (Minneap.), 14, 307

STARR, A. (1967) Brain, 90, 545

SJROKY, A., KIEICOVA, W., and YMAZAH, J. (1973) Acta neurol. scand., 49, 205

TAMLER, E., MARG, E., JAMPOLSKY, A., and NAWratzKI, I. (1959) Arch. Ophthal., 62, 657

WEBER, R. B., and DAROFF, R. B. (1971) Vision Res., II, 921

WESTHEIMER, G. (1954) Arch. Ophthal., 52, 710

YARBUS, A. (1956) Biofizika, r, 76 